\title{
Santiago de Chile, nueva arquitectura y espacio público. Arquitecturas de fin de crisis 1999-2004.
}

Santiago de Chile, new architecture and public space. Architecture of the end of the crisis. 1999-2004.

Javier Aránguiz P.

\section{Filiación}

Arquitecto P.U.C.

\section{Resumen}

Este artículo trata de un estudio comparado -siempre parcial en estos casos- del estado actual de arquitectura chilena concentrada en la ciudad de Santiago. Su valor estaría en reivindicar lo que denomino común reflexión de ciertos autores entorno a modalidades y gestiones convergentes, superando maneras particulares de hacer y diferentes escalas de intervención. No pretende más que generar, indicar de cierta manera, la conjunción de pensamientos al momento de obrar la arquitectura como objeto urbano. Esta reflexión se realiza en términos de contexto dinámico e inicio de planes operativos, que sin perder las líneas invariantes de analogía y relación a ciertas obras escogidas en este período de tiempo definido, puedan marcar el derrotero de la ciudad de cara a las propuestas de renovación urbana que se avecinan. Para esto utilizaré una escritura, que sin ser texto exhaustivo desde lo académico, se perfila como discurso apriorístico para futuras investigaciones de base objetual y ejercicio crítico. Es un intento también de síntesis de las aportaciones arquitectónicas -en clave de proyectación- refrendadas desde el germen de la economía urbana como matriz ineludible en el concepto de ciudad futura.

\section{Palabras Clave}

Arquitectura en Santiago de Chile, arquitectura como objeto urbano, casa de vidrio, plaza de armas, plaza cívica.

\begin{abstract}
This article deals with a comparative study of present chilean architecture concentrated in the city of Santiago. It points out the importance of a comprehensive thought process capable of integrating single and unrelated enterprizes to urban systems. This is accomplished by coordinating different scales and functions in order to search for the opportunity to reach a better result in terms of urban morphology and urban functions.
\end{abstract}

\section{Key words}

Architecture in Santiago de Chile, architecture as an urban objet, glass house, plaza de armas, civic plaza.

\section{Sumario}

- Introducción

Indicios y señales

Período

Selección natural

- Paisaje Cultural

Hipótesis del espejo

Obra concentrada

- Paisaje Territorial

Casa de Vidrio: Ciudad Virtual

Revista de Urbanismo №11 - Diciembre de 2004 
http://revistaurbanismo.uchile.cl

Reflexión común

Sumario

- Índice de Obras

- Catastro inicial

Costanera Norte: Túnel urbano inconexo

Cómo arrendar un sitio eriazo y revalorizarlo

Plaza de Armas: dos órdenes superficiales y la negación del subsuelo

Plaza de la ciudadanía: Poder y transformación: permanencia de lo efímero

- Colofón

"...Pero si la arquitectura chilena es, en general, buenísima creando objetos, ya sean aislados y diversos en el paisaje, ya sean autónomos y encerados sobre si mismo contextos urbanos, tiene por contrapartida el desinterés y falta de preocupación por crear sistemas de objetos interconectados y formas urbanas estructuradas $y$ entretejidas con las preexistencias ${ }^{11}$.

Josep María Montaner

\section{- Introducción}

\section{Indicios y señales}

Diría que la visión personalista del proyecto arquitectónico ya augura su rompimiento con los fenómenos de singularidad y autismo, propias de la disciplina, entendiéndose esto como la indiferencia al contexto mediante la purificación estética del contenedor aislado expresando sus máximas posibilidades compositivas.

Consecuencia de ello, los proyectos que se abordan son de carácter más de "obra" que de proyecto discursivo, y surgen mayoritariamente a través de dos mecanismos diversos pero a la vez subsidiarios en su conformación:

-por improntas de revalorización de las estructuras existentes como germen de renovación en clave económica, y

-por consolidación de las arquitecturas institucionales sobretodo universitarias como materia específica de transformación.

Esta alternancia y cruce de mecanismos quizás provendría de una mayor injerencia de los estamentos de gobierno y demás cuerpos civiles que demandan precisamente a la universidad ser el consistorio público-privado para solucionar los problemas suscitados

1 MONTANER, Josep María, introducción al suplemento "Chile, arquitectura contemporánea", en revista VISIÓN 2, J.M. Montaner, Director, Barcelona, Escuela Técnica Superior de Arquitectura de Barcelona, dic. 2003.

Revista de Urbanismo N¹1 - Diciembre de 2004 
desde los diversos ámbitos, por tanto, desde el compromiso representacional de las estamentos diligénciales.

La expresión de algunas instituciones, sobretodo de las casas de educación superior, justificarían la existencia de sistemas y ordenación de artefactos en la ciudad a partir de los ámbitos de la cultura y el conocimiento como pitares claves para el desarrollo del país. Sistemas tanto en la vertiente económica (producción) como en tas dinámicas territoriales (distribución) que inciden según la intensidad y alcance en las lógicas de competitividad a partir de la evolución tecnológica y científica aportada por estas concentraciones.

Aún lejos de señalar áreas de acción como las lógicas de distritos definidos en la ciudad europea y que en nuestro contexto serían en gran escala las zonas industriales, como en el norte de Santiago (Conchalí y Quilicura) -aún no tratadas y dejadas al arbitrio normativo-, o, en este caso, el del conocimiento como laboratorio incipiente de una red mayor de interrelación, en cambio se está cerca en señalar que hay una conformación urbana ya definida en torno a las estrategias de ubicación de las casas de estudio (clusters) y las nuevas relaciones que éstas han establecido con el tejido productivo. Relaciones tanto con las nuevas tecnologías (medicina e ingeniería entre otras) como con las de investigación social dentro del marco de las grandes reformas que ha emprendido el Estado, como las de la educación, de la salud, de la justicia y la reforma urbana.

Tal como lo señala el economista urbano Joan Trullén ${ }^{2}$, el tema de la economía del conocimiento, ya sea en la especificación de la producción manufacturera como en el desarrollo del I+D+i (Investigación+Desarrollo+innovación), toma cada vez mayor relevancia según las implicancias de la localización urbana en tanto sean parámetros de crecimiento económico y cohesión social, además de estar en relación con las economías de urbanización y de red de la ciudad. Es ahí, en esta ingente malla de análisis, diagnosis y alternativas de proposición que ofrece la vitrina universitaria, en estrecha colaboración con los planes de recualificación de las empresas productoras y de servidos, que la plataforma física de esta arquitectura comienza a adecuarse en clave programática-funcional aportando al territorio urbano artefactos engranados a los sistemas generales de la ciudad.

Bajo este escenario, y como primera etapa en la definición de piezas urbanas con valor añadido (a las que tendrán que sumarse las zonas comerciales, industriales y de servicios específicos), se hace patente el cambio de giro en la ideación del proyecto académico en general y en las escuelas de arquitectura en particular. Es el proyecto de la academia, que dentro de una política de abertura de los planes de estudios universitarios y servicios externos, se alimenta de las necesidades del consorcio público-privado como germen justificativo de sus proyectos de estudio, como así también de las investigaciones del cuerpo académico. Esto, junto al planteamiento de

2 TRULLÉN, Joan; LLADÓS, Josep, y BOIX, Rafael, en Economía del Conocimiento. Ciudad y Competitividad, "Investigaciones Regionales 1", Barcelona, Universidad Autónoma de Barcelona, Ayuntamiento y Diputación de Barcelona, julio de 2002.

Revista de Urbanismo N¹1 - Diciembre de 2004 


\section{REVISTADE \\ ISSN 0717-5051}

http://revistaurbanismo.uchile.cl

común reflexión definiéndola como la red de proyectistas que de cierta manera se agrupan por afinidad cultural y preferencias programáticas, son los substratos de implantación que redundarían finalmente en una mayor conciencia del proyecto arquitectónico hacia el espacio público en cuanto activo físico y de identidad colectiva.

Sin embargo, no se trata de realizar una antología autoral que demuestre los diferentes niveles de actualización de estos arquitectos -y sus, ahora, proyectos institucionales que a su vez se transforman según las lógicas de la clientela- sino que trata de adentrar el estudio en esta tendencia subordinada a este nivel primigenio, quizás en consonancia al estado refundacional de las estructuras de la ciudad de Santiago.

A decir verdad, la mayor parte de las obras comparadas refieren a un momento clave de la renovación multiescalar de la capital en cuanto a las confluencias de diversos proyectos de infraestructuras y sus espacios colectivos asociados.

Es la concatenación de proyectos que, como el nuevo río Mapocho debido a la construcción de la autovía Costanera Norte, una renovada Plaza de Armas con la culminación de la línea 5 del ferrocarril metropolitano hacia la Quinta Normal, la replanteada Plaza de la Ciudadanía como unidad simbólica del Barrio Cívico, y las reformadas Casa Central y Campus San Joaquín de la P. Universidad Católica de Chile como otras tantas casas de estudio, manifiestan indudablemente et estado de la cuestión.

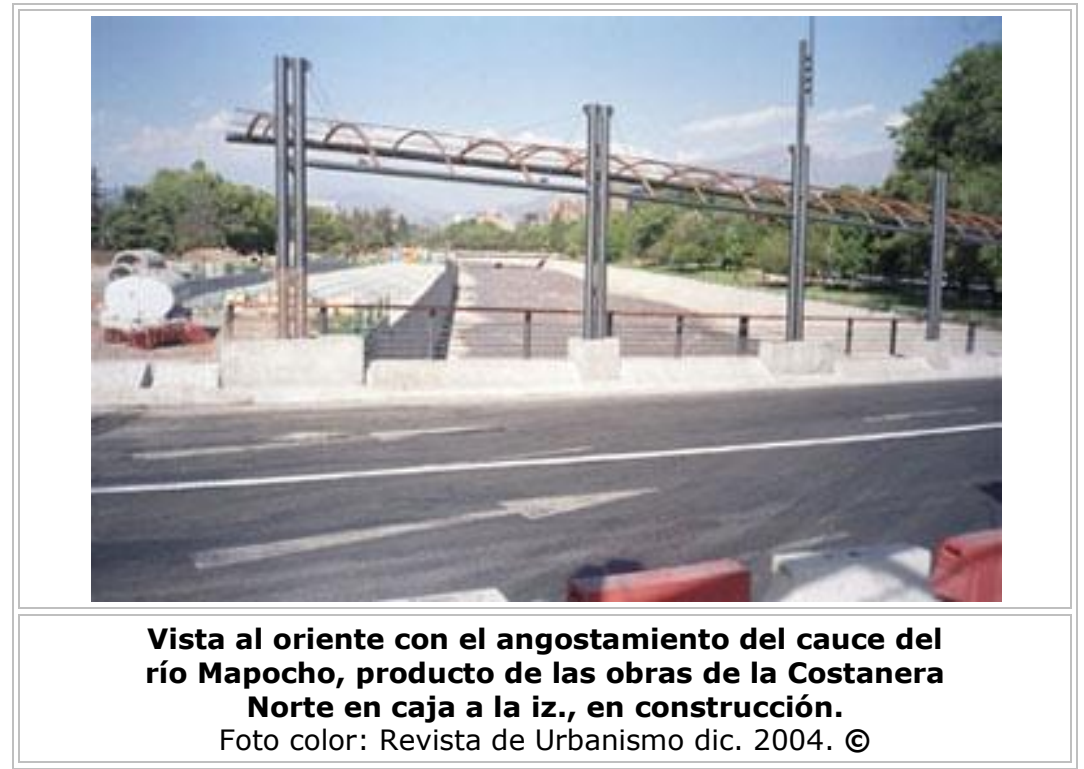


Así también el sistema de corredores verdes en Providencia y de otras comunas que van encarnando acciones concretas con el efecto directo de las obras de movilidad y de actividad como motores de la ciudad, son los puntos de un primer layer, conformando así el software de una estrategia de implantación mayor. Como también al engarce futuro de grandes espacios públicos proyectados especialmente para equipamientos y eventos como el Parque Bicentenario con el centro Cívico de Vitacura, el Zócalo Metropolitano con la sala de conciertos en el Parque del Cerro San Cristóbal y otros parques pericentrales de renovación urbana.

La casualidad ya no está a la orden del día. Lo que se inició con la "intromisión" por parte de algunas universidades al proyecto de extensión de la Línea 5 del ferrocarril metropolitano para el ordenamiento de la Plaza de Armas, ha prosperado favorablemente en la ponencia y discusión de otros proyectos urbanos. Claro ejemplo de esto, además de las consecuencias que significó el crucial debate para el trazado definitivo de la Costanera Norte -no sin traumas ni cabos sueltos aún por resolver-, es la prepuesta asociada del cinturón pericentral, el llamado Anillo interior de Santiago por parte de cuatro escuelas de arquitectura y los órganos de la administración central.

Bajo el patrocinio público y modalidades de gestión mixta, se intentará llevar a cabo proyectos de renovación del centro de la ciudad a partir de su borde histórico que marcó el primer período de su ensanche. Plan de acción que deberá conformar efectivamente nuevas centralidades y proyectos emblemáticos que dinamicen desde la base económica-social todas las áreas peri urbanas subequipadas e influyan de igual forma en la recuperación de la primera corona de municipios pobres de la capital. En este sentido deberá asumir también las potencialidades de conexión radial (o tentacular en su efecto) con el segundo anillo metropolitano, la Circunvalación Américo Vespucio, que en la actualidad se está transformado en corredor monofuncional segregado sin tener respuestas a las relaciones con los subcentros metropolitanos y nuevos mecanismos de transformación urbana.

Aún así, resalta la negación que tuvieron los promotores del nuevo sistema vial del río Mapocho a propuestas de mayor consistencia urbana de su contenido programático, bordes y superficies. Lamentablemente esta vasta operación de infraestructura no se hizo cargo del momento de refundación que inauguraba. Si es que Santiago como ciudad-capital se permite dar un salto cualitativo como metrópolis regional americana, interconectada, densa en operaciones y estratégicamente dispuesta en servicios, las demás obras que se aproximan a fuerza de un entendimiento mayor, deberán hacerlo irremediablemente.

Sin embargo, por inercia procesal de unas, o asimilación profesional consciente, de otras, se percibe, afortunadamente, una actitud proyectual solidaria desde abajo, entre obra y conformación del espacio colectivo ya sea asociado a nuevas infraestructuras o en la revalorización de vacios urbanos a diferentes escalas. A pesar de ello queda aún mucho por incidir en los otros proyectos inmediatos como las autopistas urbanas: el par Norte-Sur, el nuevo acceso Sur y los tramos ya concesionados de Américo Vespucio como vía de la nueva estructuración de la periferia. 


\section{REVISTA DE \\ ISSN 0717-5051}

http://revistaurbanismo.uchile.cl

Se podría decir que la resolución en época de crisis, es renovación al final de la crisis.

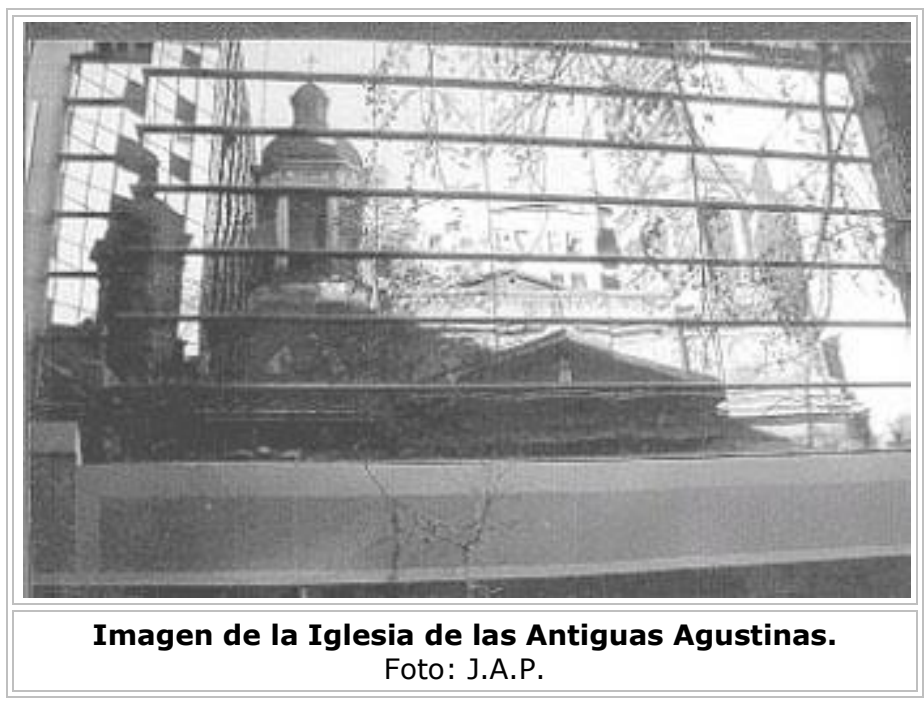

\section{Período}

Este intento de estudio se enmarca análogamente desde el final del período de ciclo económico de baja del país, que resentido por las crisis mundiales y una vez tocado fondo el año 1999, se perfiló con cierta recuperación en estos últimos años en los ámbitos visibles de la ciudad como receptáculo de las actividades de crecimiento.

Es un período que refleja los nuevos tiempos de aplicabilidad de los proyectos de expansión y consolidación institucional como modelo de actuación catalizadora de la economía. Se refieren éstos a través de parámetros instrumentales que describen la expresión de la arquitectura asociada a las grandes obras de infraestructura, tanto artefacto de actividades como sostenedor del espacio público. Sería el nivel físico beneficioso en la última cadena de eventos promovidos por una lógica de inversiones y estrategias como nuevo paradigma frente a la necesidad de crecer económicamente, pero con el compromiso social hacia niveles de mayor cohesión ciudadana, es decir, de aprobación pública.

La arquitectura que mal llamamos culta, puesto que debería denominarse quizás arquitectura de autor, es la que ínfimamente sobrevive al tráfago inmobiliario dominado por la masa comercial de construcción de viviendas y diversos equipamientos, pero que contrariamente no recaerían en ella las consecuencias estacionarias del sistema financiero. Esta inserción temporal y salida a flote se estaría produciendo afortunadamente por mecanismos de financiación focalizadas y realizadas por algunas instituciones con anterioridad a los períodos de crisis. Es el financiamiento vía créditos o aportaciones directas que dan luces a las estrategias generales de implantación y que sirven de punta de lanza para el programa institucional. Junto a 
esto, y a partir de una iniciativa estatal de "obra pública" en consolidación, se comienzan a erigir obras de variada intensidad y complejidad que se intenta sistematizar a partir de una plataforma de gestión pública privada -aún por definir- con miras a la celebración del Bicentenario de la República.

\section{Selección natural}

El texto comprende algunas aportaciones de temas y contenidos, que en forma de prólogos irán desarrollando una suerte de Índice de Obras como reflexión de este indicio y señal de la última arquitectura en Santiago. Se incorporan mayoritariamente obras de uso colectivo que incluso siendo proyectadas en el período anterior, son culminadas y habilitadas a partir de 1999. Lamentablemente la vivienda queda rezagada por su baja calidad individual como también al momento de ponderarla como mecanismo general para hacer ciudad, lo que muestra el mal estado de la cuestión habitacional en nuestro país, sea la oferta privada como el stock público.

las obras escogidas muestran generosas expresiones a pesar del momento económico en que se gestaron. Como ejemplo de esta primera generación de obras se pueden incluir la Iglesia del Sagrado Corazón del Campus San Joaquín, la Facultad de Matemáticas de la misma sede, algunos edificios de la Ciudad Empresarial -con reparos en el concepto urbanístico- y el Museo Interactivo Mirador (MIM) en et Parque Brasil de la Comuna de la Granja, entre otros proyectos ya aceptados por la divulgación especializada.

Lúcida determinación de ese momento arquitectónico fueron las ideas recogidas como las lógicas de proyecto que determinara Horacio Torrent ${ }^{3}$ en relación con que estas obras se encontraban dentro de un grupo mayor de proyectos recientes bajo determinados mecanismos de composición y de maneras de accionar. Este estudio se adentra en la selección que continúa a éstas, grupo de obras de una segunda generación, quizás de la misma cepa pero con diferente matiz respondiendo a un llamado colectivo del máximo provecho del artefacto hacia el entorno, por ende con mayor preocupación del ámbito público Tal como lo presentía el profesor Torrent, las últimas obras apuntan en mayor medida a las lógicas del sentido en tanto se trasladen a la construcción del paisaje urbano y territorial.

Como base conceptual se pretende extremar las consideraciones del estado de arte a partir de la obra paralela a este análisis como el Proyecto Nautilus, "Casa de vidrio" y su contraposición en la Autopista Corredor Oriente-Poniente, "Costanera Norte", en cuanto nueva vertebración fundante de la fisonomía de Santiago.

3 TORRENT SCHNEIDER, Horacio, "Paisajes culturales: de ahora en adelante", en: Las lógicas del proyecto, Horacio Torrent (ed.), Santiago de Chile, Ed. Arquitectura de la Facultad de Arquitectura, Diseño y Estudios Urbanos de la P. U. Católica de Chile, julio de 2000.

Revista de Urbanismo Nº11 - Diciembre de 2004 


\title{
REVISTA DE URBANISMO \\ ISSN 0717-5051
}

http://revistaurbanismo.uchile.cl

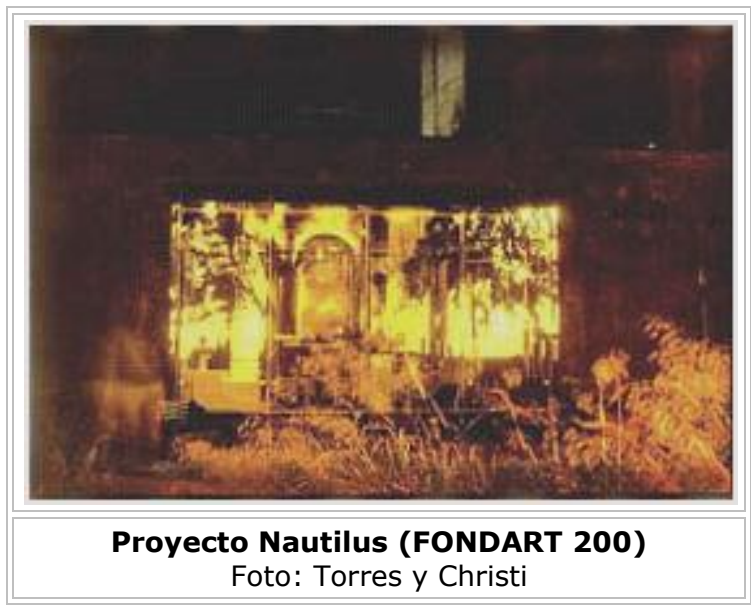

\begin{abstract}
"Ese paradigma estaría instalado en una práctica proyectual dominada por la intensidad y la superficie. (...) Hoy la construcción de nuevos paisajes culturales requiere que la arquitectura reafirme su condición de signo público, y su relación con los sentidos, con el tiempo, con el desgaste" $^{\prime 4}$.
\end{abstract}

Horacio Torrent

\section{- Paisaje Cultural}

\section{Hipótesis del espejo}

La imagen captada del Proyecto Nautilus en que el módulo vidriado -entre el destello del atardecer y las fluorescencias en penumbra- anuncia enigmáticamente los reflejos encuadrados de la antigua Iglesia de las Agustinas, quizás nos permita entrever el latente estado de la última arquitectura chilena en cuanto pensamiento y producción común. Producción que concentro y determino focalizar en un análisis de la ciudad de Santiago como marco referencial, ya que va concentrando la resolución de los problemas de renovación e intensidad según las escalas y confluencias estructurales de transformación. Todo esto en una época en que el tiempo de resolución se deja reposar en cuanto se avizoran plazos de intervención a futuro -como el inmovilismo del espejo-, pero que a la vez transcurre aceleradamente al avanzar en una nueva y cada vez mayor velocidad de morfeado de la ciudad.

Arquitectura chilena en singular y última porque sutilmente el carácter de las obras aún de pensamientos heterogéneos de formulación- presentaría grados de imaginería e improntas comunes en tanto reflejo y generación hacia el espacio público capaces de revertir la tendencia de ensimismamiento y desarticulación urbana, largamente heredadas.

\footnotetext{
4 Ibidem. 


\section{REVISTADE \\ ISSN 0717-5051}

http://revistaurbanismo.uchile.cl

Cabe decir que esta supuesta asimilación colectiva entraría, por tanto, a través de dos afluentes: uno a manera conceptual como modo de intercambio de ideas y opiniones que se van generalizando y aceptando como consideraciones comunes en el ambiente de los proyectistas, y otra a nivel formal en cuanto al tratamiento y acabado matérico identificables de la forma expuesta. Es la forma marcada por los sellos del neomodernismo y empirismos europeos del último lustro, en que el trabajo ajustado de la envolvente (resolución estructura y cerramiento) pasa a ser el paradigma en la lógica actual al proponer alternativas de construcción según parámetros variables y de reacción rápida frente a diversos escenarios de aplicación.

La transparencia inicial que muestra esta segunda imagen del Proyecto Nautilus, del vidrio superado por el instante de opacidad reflectante y que conjura en la misma superficie en forma simultánea las distintas apariciones de la iglesia, de los cuerpos edificados y a su vez del mismo proyecto en transparencia, da indicio a que el paisaje cultural de la arquitectura santiaguina podría intuir a que el estado de arte de los proyectos -lo viejo y lo nuevo, lo Lleno y lo vacío- quedara sellado en un mismo continente de actuación.

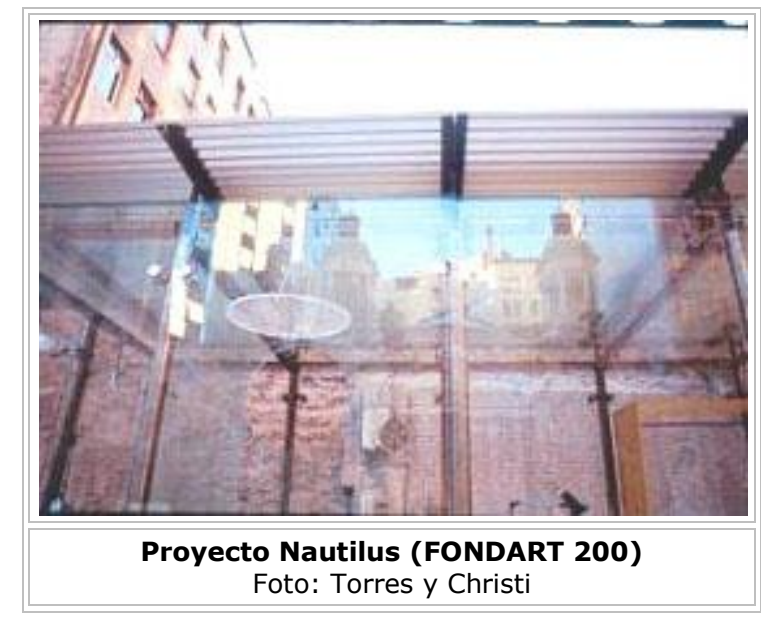

Se plantea sintéticamente este fenómeno como el resultado conceptual que se desprende entre la agrupación de diversas imágenes individuales (lo heterogéneo de los proyectos), que estando desligadas inicialmente unas de otras, finalmente frente al "espejo", -acción buscada o no de sus operaciones en cuanto oficio, difusión y crítica-, la separación del objeto se difumina para dar paso a una composición amalgamada de imágenes capturadas por el lente observador (lo homogéneo de la común reflexión).

¿Será quizás que las diferentes obras de arquitectura -en subyacente actitud de sus autores- busquen ese espíritu de acercamiento con tal de hacer aparecer mancomunadamente sus frutos en conjunto y no por separado? 
http://revistaurbanismo.uchile.cl

¿Será quizás que en la proyección del "espejo" como buena inserción en la ciudad, se tratarían de esconder sus defectos más inmediatos pero, a la vez, se destacarían sus virtudes en común como efecto reflexivo en la conformación del espacio público?

¿Será, quizás, que frente al espejo, todos somos iguales, ... in intentamos serlo?

\section{Obra concentrada}

Es la hipótesis de cómo el fenómeno de la arquitectura de autor, en cuanto a los grados aplicabilidad de la profesión incubada en la academia, se va dando por un lado, mediante procesos de adjudicación en forma directa y sin mediar selección (la demanda del arquitecto ya consagrado), y por otro, en contextos de concentración del tejido urbano a partir de encargos de primer cliente y concursos abiertos. Es decir, de una anterior dispersión proyectual se estaría adentrando a una red concentrada de proyectos interrelacionados que pueden demostrar un patrón común de comportamiento en cuanto a su gestión y alcances de resolución del programa, sería entorno a los conceptos de activación urbana, dentro de los cuales el del conocimiento aparece como el más promisorio a desarrollar en cuanto a su condición de concentración. De ahí que uno de los rasgos característicos de este momento es el cambio de la dialéctica del proyecto en cuestión: la obra aislada deja de serlo para pasar a la ser "estructural", en que el proyecto de arquitectura autoral del que hablamos ya no se dispone en las afueras de la ciudad, en los lugares remotos apartados, como segundas viviendas u obras experimentales, sino que se dispone lentamente en la ciudad, ya en el centro, ya en sus periferias, bajo estrategias de localización y escalas de intervención territorial.

Esta imagen metafórica de la casa de vidrio que ofrece el Proyecto Nautilus no es de por sí nueva, aunque quizás renovadora de las categorías de análisis dispuestas entorno a los regionalismos críticos y modernismos apropiados expresados en las aproximaciones tectónicas, sobre todo en el carácter de obra única. Nos podría dar señales quizás definitorias en la concepción teórica-práctica para estos momentos de expectante desenlace en el buen proceder de la ciudad y su entorno territorial más inmediato. 


\section{REVISTA DE URBANISMO \\ ISSN 0717-5051}

http://revistaurbanismo.uchile.cl

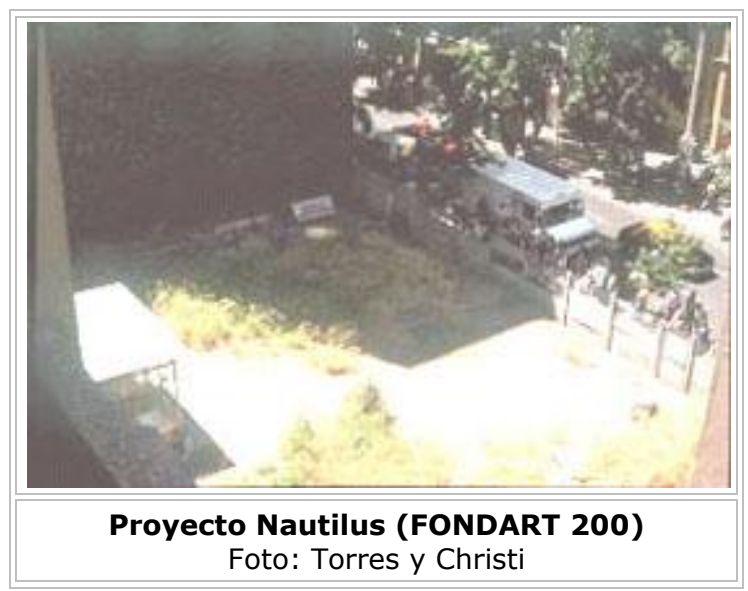

"¿Santiago? Haciendo caso omiso de la lapidaria divisa de Mies van der Rohe, 'less is more', podemos pasar despreocupadamente, tal vez, a la lejanía geográfica y temporal de un mítico pabellón de una feria universal a un sencillo baño parado en la mitad de un parque comunal" ${ }^{5}$.

Manuel Corrádá y Smilján Rádic

\section{- Paisaje Territorial}

\section{Casa de vidrio: Ciudad virtual}

Esta instalación tan efímera como de memoria persistente se deja mostrar a pesar del delirio mediático que significó su irrupción en aquel verano del 2001. Como una suerte de icono que manifiesta ese límite tan sutil como atroz entre el objeto construido y su relación con el espacio público, es que presentó su valorización -más que por sus cualidades arquitectónicas- por su trasfondo significante de la reacción ciudadana y activador económico.

la ubicación estratégica del habitáculo en el entonces sitio eriazo frente a la antigua Iglesia de las Agustinas en clara antítesis al presentarse ésta devorada por los edificios contiguos, en pleno distrito fundacional de Santiago y a pasos de la Plaza de la Ciudadanía, no es baladí. Su expresión cúbica transparente, posada en el tierral pero elevada del suelo y cercana a las medianerías de adobe y testeras de altos edificios, son signos preclaros del descalce que se produce -y hago el salto- entre las

5 CORRADA, Manuel y RADIC, Smiljan, "Hopeland: Santiago", en: El lugar de la Arquitectura, Alejandro Aravena Mori (Ed.), Santiago de Chile, Ed. ARQ, Escuela de Arquitectura de la P. Universidad Católica de Chile, diciembre de 2002.

Revista de Urbanismo N¹1 - Diciembre de 2004 


\section{REVISTA DE URBANISMO \\ ISSN 0717-5051}

http://revistaurbanismo.uchile.cl

aportaciones de las arquitecturas y sus consabidas intenciones, casi siempre malogradas, de dialogar con el espacio público. Observación que se tendrá de sustento en la imagen de la virtualidad de la ciudad y el desarrollo que sigue en este estudio comparado de obras y que el Proyecto Nautilus es el iniciador del Índice de obras.

\section{Reflexión común}

En este sentido, esta presentación de ideas puede incitar a la revisión del estado que demuestra la acelerada cercanía entre periferia y centro cultural (Chile-Europa) que viene de manifiesto en la observancia del arquitecto Rafael Moneo que hace del ámbito arquitectónico chileno: "...cuyas minorías más avanzadas han apuntado inevitablemente la aguja de la brújula hacia Europa, la arquitectura chilena se ha desarrollado en relación a la conquistada proximidad de sus fuentes, persiguiendo el programa de ser actualizada entendiendo esta condición como prueba de hecho que es disponible satisfacer la aspiración de anular la distancia"6. Como si el reflejo frente a las preexistencias de la ciudad, hiciera revisar la disposición del grupo autoral frente a los encargos, ya más en la línea de un coro polifónico, que en alardes de voces individuales. En ese auscultar de la imagen urbana pareciera haber una suerte de consenso en el círculo profesional-académico en cuanto a pensamiento y unidad de la forma (concepto y estilo), toda vez que hay una ausencia de un cuerpo de verdadera crítica arquitectónica. Parafraseando a Moneo, cabe la observación de procesar la anulación de la distancia entre los mismos arquitectos del medio, configurando centro y periferia a la vez y que virtualmente dan señas de ser los únicos maestros y oficiantes entre sus pares, ya que el grupo selecto es pequeño, repetitivo y asiduo al mismo ámbito universitario.

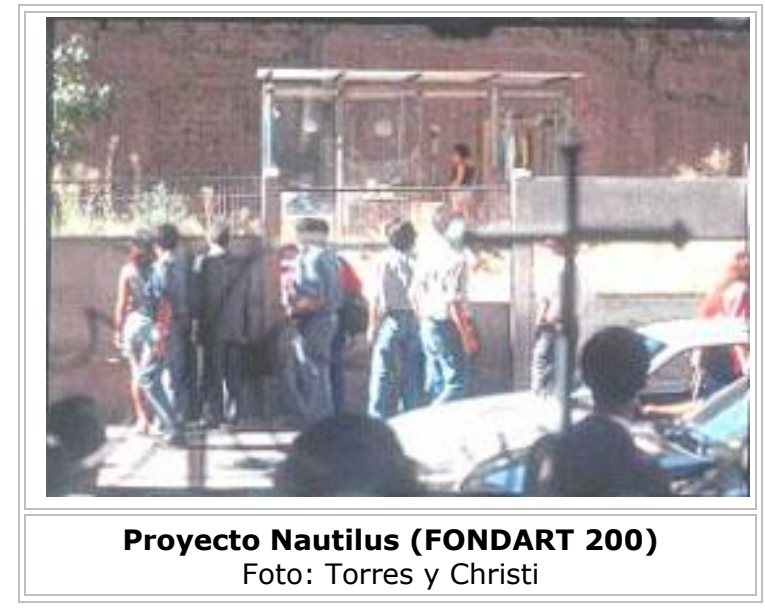

6 MONEO, Rafael, "Architettura e globalizzazione. Alcune reflessioni a partire dalle vicende dell'architettura cilena contemporanea", editorial de la revista CASSABELLA N650, noviembre de 1997 . Citado y traducido por Horacio Torrent, "Posibilidades edificantes", en: Arquitectura reciente en Chile: las lógicas del proyecto, Santiago de Chile, Ed. Arquitectura de la Fac. de Arquitectura, Diseño y Estudios Urbanos de la P. U. Católica de Chile, julio de 2000.

Revista de Urbanismo N¹1 - Diciembre de 2004 
Esta virtual unidad ha llevado coincidentemente el accionar de los profesionales a proyectos más trascendentes, a proyectos "estructurales" y que se perfilan más densos, con más sustancia en cuanto a programa y gestión, ligados escalarmente a la ciudad como ente expresado en la tensión urbana y su renovación de infraestructuras y equipamientos culturales.

El desarrollo y la madurez en unos, como la consolidación formal en otros, se manifiesta en un selecto grupo de arquitectos más bien prácticos que teóricos -y que, a diferencia de lo que apresuradamente Aravena Mori llama "Escuela de Santiago"7 a propósito con un nombre cogido de un colectivo de arte con vigencia en la década de los 80',- propondría incluir activamente a los: Cruz Ovalle, Fernández Larrañaga, Klotz Germain, Undurraga Saavedra y eventualmente al mismo Aravena Mori.

Conjuntamente al cristalizar la problemática expuesta, se está en este "mirarse entre ellos", en apoyarse en forma explícita o indirecta, comenzando a diseminar proyectos altamente cualificados y de índole programática definida, que ligados a las instituciones educacionales (colegios, institutos y universidades), por tanto apoyados por un fuerte soporte financiero, dan tendencia prioritaria en la consolidación de las nuevas estructuras funcionales desde la escala del proyecto arquitectónico.

\section{Sumario}

Se presenta esta lista comparada de obras a manera de índice casuístico de proyectos arquitectónicos realizados de un tiempo a esta parte que, más que seleccionados a base de criterios antojadizos y discrecionales por sus planteamientos, son resaltados como obras de calidad manifiesta en cuanto a su momento de aparición (paisaje cultural) y de asimilación con el contexto urbano (paisaje territorial).

Sería la reflexión más pausada en el acontecer de la ciudad, y que al momento de ser revistados, el punto de vista crítico que intento recoger podrá dar nuevas aportaciones como también el comprobar el discurso inicial propuesto versus la integración con el contexto, pasado algún tiempo después de su gestación. Quizás será buscar esa dimensión aletargada de la visión subjetiva que se manifiesta desde el golpe de vista de su concreción espacial -construcción inmediata- hasta en el transcurrir del tiempo en sus transformaciones y ajustes, respondiendo a esas demandas sutiles, casi invisibles, del vivir en la ciudad y sus diferentes grados de intensidad.

Este índice trata de una lista analítica de obras en tanto reveladora del estado de situación proyectual, queriendo originar tentativamente un plano topológico en la distribución de la ciudad Santiago, soporte que posibilite conectar físicamente líneas de tensión y relación de áreas unitarias como germen de efectiva renovación urbanística. A esto se suma el identificar, aunque sea someramente, los patrones de organización en que se asientan los fenómenos de renovación y de aglomeración de actividades bajo conceptos de la economía urbana.

7 ARAVENA M., Alejandro, Conversaciones, en: El lugar de la arquitectura, Alejandro Aravena Mori (Ed.), Santiago de Chile, Ed. Arq., Escuela de Arquitectura de la P. U. Católica de Chile, diciembre de 2002. Revista de Urbanismo N¹1 - Diciembre de 2004 


\section{http://revistaurbanismo.uchile.cl}

Ya sea en la renovación de las áreas de centralidad del espacio público como en la implementación o remodelación en los ambientes periféricos con nuevos artefactos, las dos instancias presuponen maneras de engarce en el sistema general de la ciudadvialidad, transporte, zonas de intensidad de uso de suelo- atendiendo a sus tipos y morfologías específicas. El juego ensayístico se presenta en que el Índice de obras no será estático en tanto a la determinación de las obras como lista cerrada, sino que será cambiante, ya que la idea es ir incluyendo nuevos proyectos siempre habrá "proyectos recientes"- que, dentro del esquema compositivo y de categorías comparativas, irán enriqueciendo la dialéctica del paisaje cultural y territorial como proceso prospéctico de la ciudad.

Las reseñas de la Plaza de Armas y el proyecto Costanera Norte introducirán a manera de prolegómeno el catastro de obras en su doble juego de pivote analógico. La disposición correlativa de los proyectos que sigue a continuación, tiene la intención de ponderar una jerarquía asociada en el sentido de obra señera en las escalas de intervención y no en una especie de "Ránking" de mayor a menor valoración.

\section{- Índice de obras}

(1). Casa de Vidrio: Proyecto Nautilus". Paradigmática. Estudio de sus consecuencias culturales. Tesis: significó entre otras cosas la valoración del predio eriazo para la construcción del mall y patio de comidas. ¿Cómo sería replicar lo misma situación en otro lugar? Cruce conceptual con los nuevos proyectos. Paradoja instalación - obra urbana.

(2). Facultades de la P. Universidad Católica de Chile: Modelo de ciudades universitarias con fuerte huella de los espacios públicos. Es la abertura de la universidad como casa matriz interdisciplinar en las aplicaciones de la vida civil. Implicancia de las Políticas Públicas, pero con autocomplacencia en el carácter de los espacios logrados.

(2.1). Remodelación y ampliación del campus San Joaquín, Comuna de Macul: Facultad de Matemáticas, Ingeniería, Construcción Civil, Enfermería, Historia, Letras, Educación, Dictuc. Además de centros de servicios universitarios e Iglesia Central. Del Plan de Brandes hacia la cordillera, se ha volcado su frente a Vicuña Mackenna en directa relación a la conectividad estructural del Metro. Que los centros de servicios no se transformen en la justificación del uso comunitario.

(2.2). Remodelación campus Casa Central, Comuna de Santiago: Facultad de Comunicaciones, ampliación Escuela de Medicina y obras anexas. Densificación a tres niveles. Se contrastan dos tipos de proyectos. Los proyectos que tuvieron que entrar con calzador y que demoraron bastante tiempo en su definición (los de los claustros interiores) y los de nueva planta que se pretende levantar fuera del recinto corno centro universitario en una tipología mixta entre edificio compacto, plaza elevada y torre de servicios.

Revista de Urbanismo Nº11 - Diciembre de 2004 
(3). Campus Peñalolén de la Universidad Adolfo Ibáñez: José Cruz Ovalle Arquitectos Asociados. Como de la idea de "casa de retiro" a lo de monasterio benedictino, se convierte en ágora del conocimiento. Cómo la rapidez del proyecto y construcción llevó a un planteamiento que, sin dejar de ser complejo en su partido general, omite una serie de aproximaciones de detalle constructivo como impronta específica del autor. Es la idea del silencio del entorno versus la ebullición de ideas pragmáticas como laboratorio de economía y política. Contraposición entre su eventual balconamiento y el carácter cerrado de sus patios que no permite una extensión abierta hacia el horizonte del valle.

(4). Sala de Actos XL Matucana 100: Martín Hurtado arquitecto. Del teatro callejero a la sala convencional de eventos. ¿Cómo se articulan los dos mundos?. Se oficializa, mediante una forma contenida en clara alusión tectónica, la manifestación marginal y lúdica que significó este complejo artístico. El planteamiento de doble caja de madera incrustado a la antigua fábrica de albañilería renueva los mecanismos de apropiación y asimilación del colectivo artístico. La componente vertical faltante es suplida con acierto por las proporciones de la sala. Falta, ostensiblemente, la relación con el entorno (Quinta Normal).

(5). Facultad de Arquitectura do la Universidad Finis Terrae: Moreno Arquitectos. Cómo de un agregado de nueva impronta se adecua, mediante el mantenimiento del jardín como patio, a la edificación preexistente (palacete francés). Se intenta disponer el programa de escuela de arquitectura en un solo contenedor de carácter urbano, componedor de las escalas constructivas cercanas. El liberar la esquina en la planta baja no supone siempre la interacción en continuidad con el espacio público (irejas!). Problema de espacios polivalente no previstos en el diseño de aulas.

(6). Colegio Altamira en Peñalolén: Mathias Klotz arquitecto. Es la consecución espacial de un sistema educativo libre e interactivo que, sin embargo, es conducida por la neta definición compositiva en relación al paisaje Se logra disponer los elementos de barra perimetral abierta que otorgan flexibilidad a la plataforma inclinada tanto al aire libre como en el espacio inferior. Se está frente a un proyecto de arquitectura cabal confinando forma -no tanto el uso en un muy buen artefacto urbano. Se divisa la tensión visual a la Universidad Adolfo Ibáñez.

(7). Museo de Artes Visuales, Plaza Mulato Gil de Castro: Undurraga y Devés arquitectos. Buena inserción por contraste y escala pero no del todo en cuanto al espacio interior de exhibición. El despeje total escalonado agota de inmediato las posibilidades de tensión que pudieran suceder al recorrerlo hasta los niveles subterráneos. Interesa más como remate de la secuencia de escalas peatonales de la calle Lastarria, que como capacidad de invención arquitectónica que pueda ofrecer el edificio.

(8). Pabellón de Suboficiales del Ejército de Chile: Mathias Klotz arquitecto. Que la imagen institucional castrense busque nuevas expresiones es ya de por sí importante. Los guiños de un supuesto plasticismo moderno son evidentes sobre todo en la concepción de la planta baja entre lo que es estructura y cerramiento. Este pabellón, a 


\section{REVISTA DE URBANISMO \\ ISSN 0717-5051}

http://revistaurbanismo.uchile.cl

la espera de la construcción de un segundo anexo, tendrá que referirse a un plan maestro de ordenación general del conjunto. Cabría señalar también una revisión como espacio libre (verde privado en este caso a todo ese paño en relación a la Penitenciaría y a la renovación que se está gestando por el frente del Parque O'Higgins.

(9). Ampliación del Seminario Pontificio Mayor, Propedeútico en la Florida: Cristián Fernández Cox arquitectos. Es el último proyecto de ampliación y renovación del Seminario Mayor en cuanto corolario histórico de diversos proyectos y cambios estilísticos. Pasa a ser el culmine de ir muestrario, un itinerario formal cambiante -no así equícovo- del autor pero que, sin embargo, como es planteado, el proyecto total va aceptando estas ampliaciones en un sutil mecanismo unitario de llenos y vacíos. Analogía al crecimiento de la ciudad.

(10). Plaza Plástica calle Monjitas: Plaza de acceso a Estación Bellas Artes de la Línea 5 del Metro, Iglesis Prat, arquitectos. Pareciera ser un resabio artístico, un dechado formal de alta calidad, pero que no es otra cosa que al ajuste del único acceso a la estación del Metro al solar de la esquina. Aún así, la composición da paso a un notable lugar de apertura y posibilidad de encuentro.

\section{- Catastro inicial}

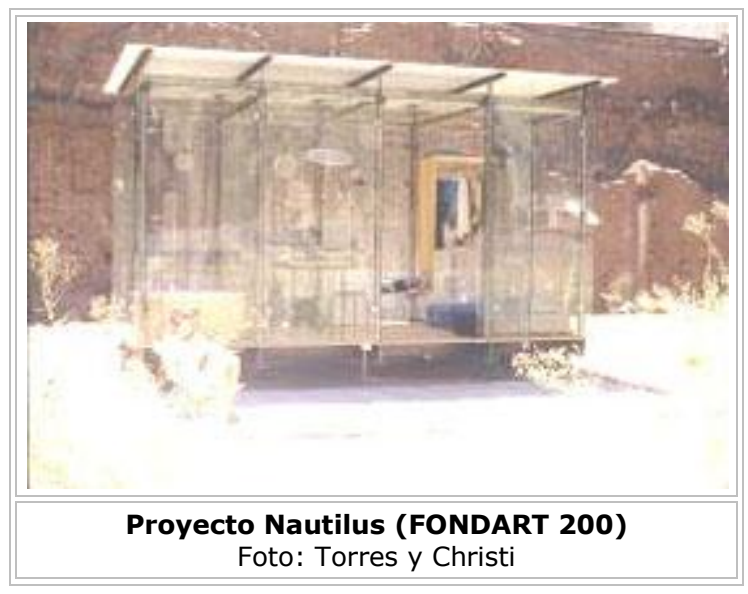

\section{Cómo arrendar un sitio eriazo y revalorizarlo}

Es la primera obra escogida y por tal, más que por un inicio cronológico, quizás por ser pivote de todo el proceso crítico en las propuestas arquitectónicas desde el ámbito del grupo de trabajo autoral, en cuanto cuna de ideas y tendencias. Valga puntualizar la, hasta ahora, no pertenencia de los autores a lo que he llamado "común reflexión" y que demuestra paradójicamente los compartimentos estancos aún del pensamiento arquitectónico.

El recobrar la Casa de vidrio interesa por las siguientes razones: 
http://revistaurbanismo.uchile.cl

- Como ejercicio cultural para agitar nuestra delicada memoria y repasar un suceso a todas luces transformador de las lecturas del componente público.

- Para inferir temáticas menos epidérmicas a las ya declaradas, esto en relación con las estrategias de implementar el habitáculo a partir de las decisiones de ubicación respecto a un solar céntrico. Que este sitio reclamara tal desatención y precariedad en un entorno altamente activo es ya una gran evidencia.

- Esta revisión puede transformarse en visualizar cómo una intervención de este tipo significa la revalorización del predio vacío en cuanto a expectación de rentabilizar la "plusvalía" generada por el revuelo público e iniciar, ya sea por iniciativas propias o presiones inmobiliarias, la construcción de un contenedor capaz de generar actividad. Después del Proyecto Nautilus, sucedió en la parcela una operación mediante la construcción de un edificio mixto, de estacionamientos y patio de comidas. Cabe la sorpresa que al parecer no se llegó a edificar todo el volumen edificable que le permitía la normativa.

El fenómeno de la transparencia en la habitabilidad de la Casa de vidrio, que demuestra el conflicto entre el interior-exterior, por no decir lo público y lo privado, viene a ser secundario en cuanto a la temática implícita que la genera. Su aparición subvierte el tema objeto-vacío en relación al implante que se produce desde el artefacto arquitectónico en el descampado del sitio baldío (espacio público). La disposición paralela en el emplazamiento del solar, la distancia medida a la línea de cierro -que señala las premeditadas oberturas y cerramientos para los paseantes- , el contraste tectónico frente al muro posterior de adobe y la intencionalidad neta en los acabados domésticos de piso y techo, no hacen más que reflejar su condición de receptáculo crítico en la concepción del proyecto genérico que, en general, no introduce términos de diálogo con el espacio socio-físico.

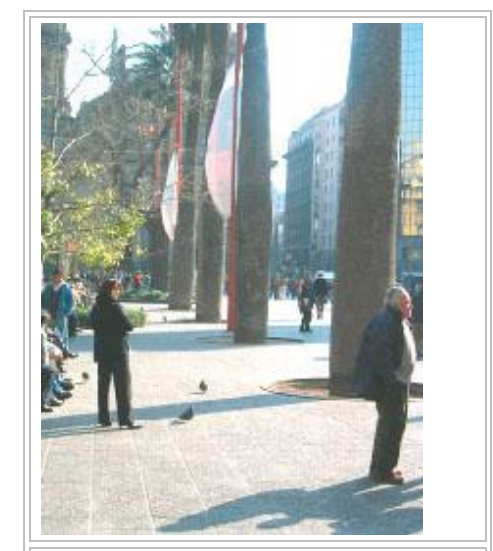

Plaza de Armas de Santiago de Chile, hacia la Catedral. Foto: J.A.P. 


\section{Plaza de Armas: dos órdenes superficiales y la negación del subsuelo}

Su condición de vacío predeterminado acentúa el tratamiento formal a nivel de reubicación de las piezas interiores, sin que cuajen todavía en tanto percepción ambiental y espacio representativo. Hay que entender la remodelación de la plaza dentro de las oportunidades que se generaron por la construcción de la Línea 5 del Metropolitano desde la estación Baquedano en dirección a Santa Ana y, ahora, hasta la Quinta Normal. La disposición de una estación en este cruce -a todas luces insuficiente al lugar, porque ni siquiera es de intercambio como se debería suponer- significó la construcción a tajo abierto del subsuelo, lo que trajo grandes consecuencias de transformación a nivel de superficie, pero no en su circulación vertical.

A partir de la coordinación institucional con las universidades y mediante concurso público se llevó a cabo la remodelación del vacío fundacional de Santiago, bajo las premisas de despeje espacial de dos de sus frentes y la concentración vegetal y de mobiliario urbano en uno de sus cuadrantes. El transcurrir histórico de la Plaza de Armas, en cuanto plataforma dura que acogía las actividades efímeras de la ciudad feria, desfile, procesión-, su "ablandamiento" a partir de la valoración decimonónica como jardín aburguesado $y$, posteriormente, su decaimiento, producto de su conformación anacrónica, se ha posicionado como un fuerte artefacto urbano, más que por el realce estratégico de la edificación patrimonial de sus inmediaciones, por su encaje dentro del sistema peatonal modélico de la ciudad. Como tal, la plaza se ha reducido al cuadrante nororiente, dejando su carácter estanco al paso continuo de alto flujo de las calles peatonalizadas de Ahumada y Puente.

En efecto, la Plaza de Armas se puede leer desde la perspectiva del ensanchamiento del sistema pedestre en la tensión que genera la Alameda [Avda. del Libertador B.O'Higgins] y el sector de Mapocho y la urdiembre del sistema de las galerías intermanzanas. Esta refundación es explícita por cuanto permite nuevas actividades de concentración que en forma inmediata se instalan en sus franjas frente a la catedral y borde cívico de la municipalidad. Los puestos de pintura, cafés y círculos de orantes no hacen más que recobrar el sentido original de la plataforma, que en forma espacial recuerdan las antiguas plazas-mercado pero donde, indudablemente, hace falta un plan de reordenamiento volumétrico para su permanencia.

Hilando fino, se podría llegar a conformar un orden espacial secuencial, entre la escala de los edificios perimetrales y el carácter autónomo de la masa vegetal que recrea en cierta forma un nuevo paradigma de paisaje natural entre un ordenamiento vertical (las palmas) y un aparente caos en la disposición accidental del "sotobosque" (jardineras, mobiliario). Esta propuesta intermedia vendría a articular estos órdenes en la disposición de volúmenes alternados vidreados, de pequeño calibre que alberguen los usos que actualmente se producen, además de dar connotación a las placas del subsuelo.

\section{Costanera Norte: Túnel urbano inconexo}




\section{REVISTA DE URBANISMO}

ISSN 0717-5051

http://revistaurbanismo.uchile.cl

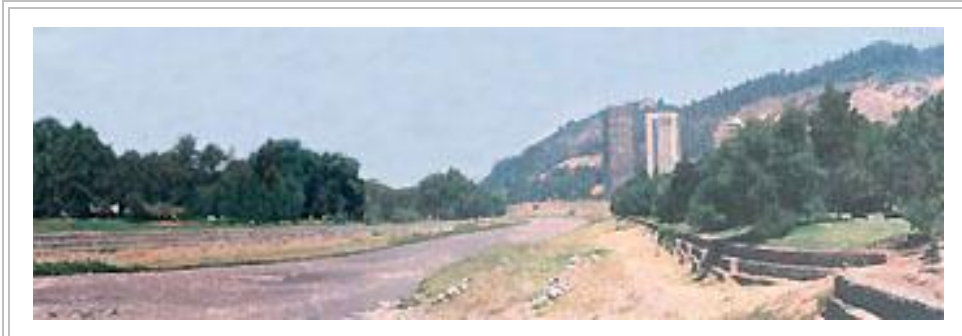

Río Mapocho antes de la intervención de la Costanera Norte.

Foto: Revista de Urbanismo, 2000. (C)
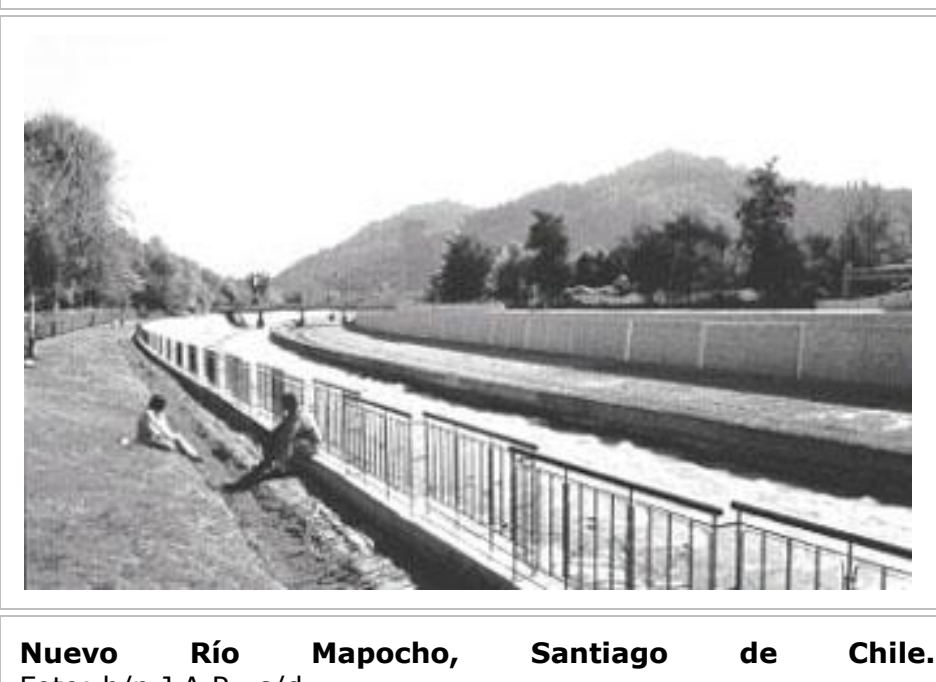

Foto: b/n J.A.P., s/d.

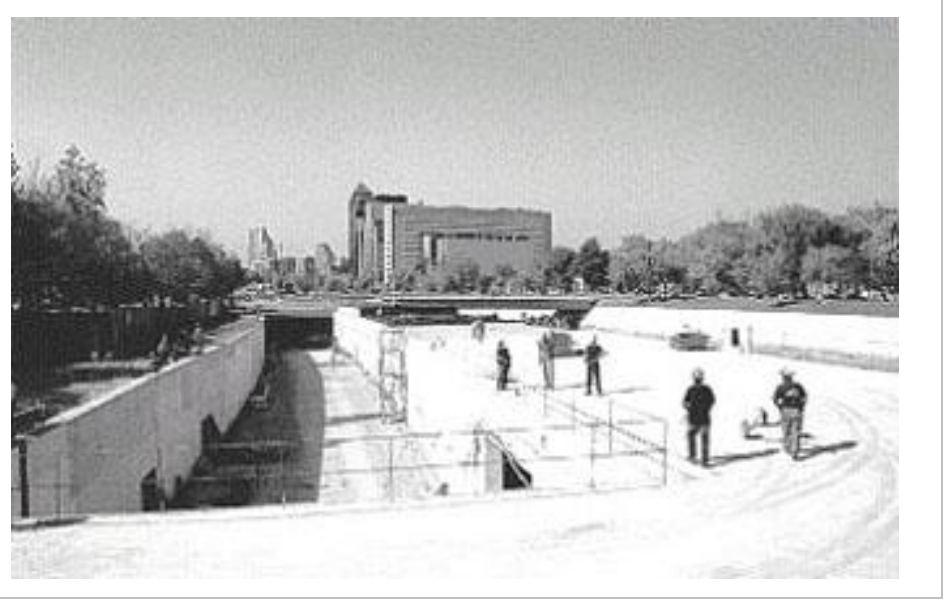

Nuevo Río Mapocho, Santiago de Chile, en construcción. Foto: J.A.P., s/d. 


\section{REVISTA DE \\ ISSN 0717-5051}

http://revistaurbanismo.uchile.cl

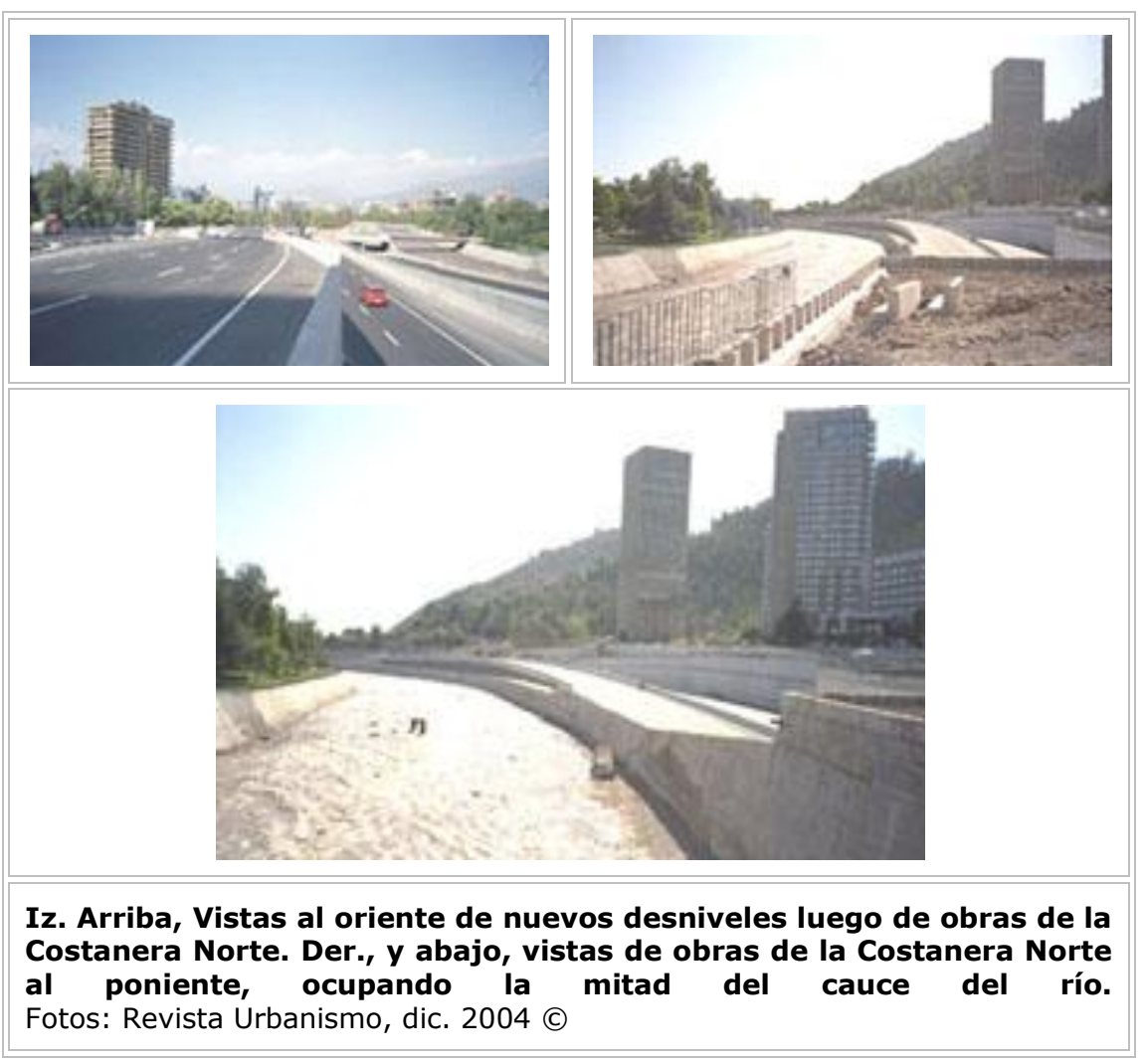

Capítulo aparte sería ahondar nuevamente en las consideraciones de la Costanera Norte en cuanto a su trazado definitivo. No por eso es válido dejar pasar algunas inquietudes antes de su funcionamiento. Es de perogrullo decir que su implantación no es provechosa en la generación de nuevos puntos y continuidades para el tejido de la ciudad. Pero la cuestión viene en poder asimilar sus deficiencias y transformarlas en oportunidades una vez que avance su funcionamiento y se puedan negociar nuevas condiciones de intervención a partir del contrato de concesión. Descontando la construcción de un programa lúdico navegable que complementaría el futuro Parque Bicentenario de Vitacura, no aparecen mayores proyectos de carácter urbano que potencien sus actividades. El proyecto de la Costanera Norte, más que acentuarlo en la crítica de la menudencia en su resolución de puentes y salidas vehiculares, lo presentaría en el problema aún no resuelto de haber desaprovechado su potencial intensidad como condición operativa a nuevas actividades centrales (relación inmediata al cinturón pericentral). Así tampoco a puntos de intercambio de medios que profiten de los altos flujos vehiculares. A esta contradicción ontológica le he dado la imagen de ser una especie "de Línea de Metro sin estaciones", o sea, la de un gran corredor de desplazamiento oriente-poniente sin los convenientes puntos de alimentación que sustenten la intermodalidad de sus flujos y otras actividades complementarias que fortalecerían sus frentes de excedencia económica. Es además, el abortar en su trazado la posibilidad de transporte público soterrado y asociarlo éste a puntos de 
http://revistaurbanismo.uchile.cl

intercambio (estacionamientos, servicios automotrices, comercio, etc.,) y su efectos indiscutibles en la potenciación de lugares urbanos claves que hacen muy difícil su inmediata mejora como mecanismo de reconversión. Por ahora -y a manera de caso concreto- no cabría más que urdirlo al proyecto del "Zócalo Metropolitano" (parque, anfiteatro, sala de conciertos) como antiguo trazado de la autopista a pie de cerro, con toda la problemática de transformación que eso implica.

\section{Plaza de la ciudadanía: Poder y transformación: permanencia de lo efímero}

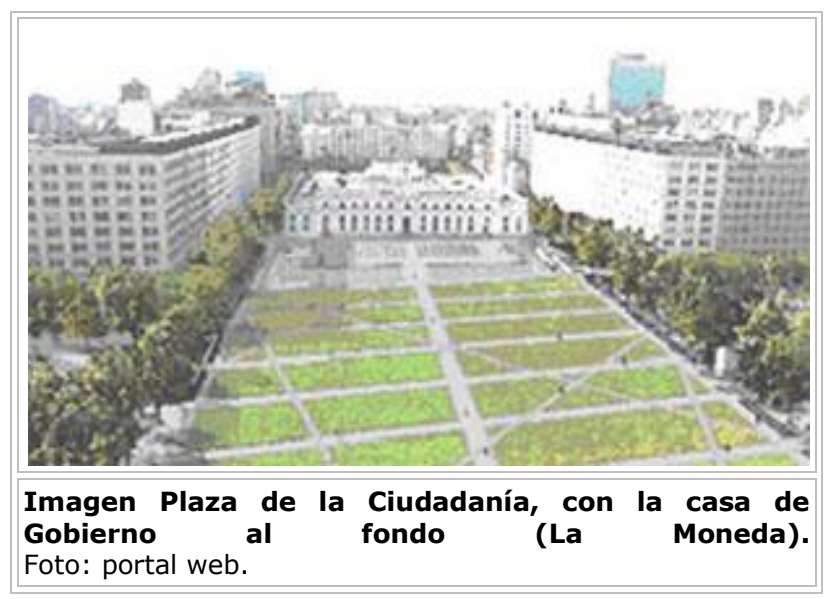

Es resultado, aunque parcial, de un largo camino de proyectos y alternativas de intervención para el ordenamiento del Barrio Cívico de Santiago, el cual aún no termina ${ }^{8}$. Es la expresión en el cambio de concepción del lugar, que iniciando su imagen en la completitud de los cuerpos edificados de su perímetro (ministerios, paseo Bulnes), la connotación en su carga sociocultural hace que a este proyecto monumental se le observe bajo el prisma de vado urbano a intervenir, artefacto moderno que dé lugar a la acogida ceremonial y espontaneidad del rito público. La simplicidad pero, a la vez, la rotundez del gesto espacial del proyecto recientemente iniciado por la oficina Undurraga y Devés no es más que la expresión mayor y en clave de superficie operativa al plantearse la plataforma que intenta contrarrestar -mediante la mínima expresión- las variadas circulaciones, usos y potenciales espacios de congregación multitudinaria.

Esta conciencia del proyecto hará que, a no mediar un ajuste en el tratamiento del mobiliario urbano y de los pavimentos, se pierda en algunas áreas el sentido de lugar apto para la actividad libre como expresión y continuidad de lo efímero. Siendo la Plaza de la Ciudadanía el entorno del Palacio de la Moneda, el punto neurálgico del poder político, pero contrario a ser una centralidad de actividad vital de la ciudad, se actúa bajo el concepto que a mayor presión y necesidad de espacios libres, se soterren forzadamente las vías de circulación y todos los demás equipamientos que mantienen

8 ARÁNGUIZ P., Javier, en Tesis Proyecto de título "Ministerios del territorio: Remate del Paseo Bulnes", aula de titulación Urrejola-Undurraga, Santiago de Chile, Biblioteca Lo Contador, F.A.D. y E.U. de la P. U. católica de Chile, diciembre de 2001.

Revista de Urbanismo Nº11 - Diciembre de 2004 
esta operación de recualificación urbana. EL proyecto es inteligente en minimizar las complejidades formales y de desnivel del terreno, pero inseguro y ambiguo en tanto a la condición de parque reducido a un llano semirígido que propone.

Además que su actuación pueda repercutir realmente en la renovación del sector, es la incógnita a resolver más allá de liberar la superficie con estacionamientos y servicios subterráneos, agregando a medio camino el Centro Internacional de las Culturas (CIC) como gancho de atracción. No olvidemos que tanto el completar el eje Bulnes, como su eternamente postergado remate, son piezas a considerar desde ya, aunque la idea de los ministerios del territorio (ministerio de obras públicas y de vivienda y urbanismo) esté momentáneamente sepultada.

\section{- Colofón}

Este artículo, cuya intención es transformarse en un breve ensayo, contiene puntos para una disposición expectante pero optimista del quehacer arquitectónico chileno en el ámbito de la ciudad. Viene desde el punto de vista de las oportunidades y mecanismos innegables de transformación que se han preparado desde la plataforma pública-privada en aras a la reconversión física de nuestro territorio y en especial del caso de esta ciudad como concentración de la problemática urbana actual.

Pues dentro de este marco, las renovaciones que se plantean multiescalarmente en varias de nuestras ciudades, y en especial a la atención que requiere Santiago como fenómeno en permanente expansión, es que esta indagación que planteo a través de casos comparados, no viene más que a proponer nuevas vetas de la implantación de la actividad que enrielen las tan ansiadas reformas en el ámbito de lo urbano (planificación, economía), eso sí, siempre subalternas a los componentes que demanda el espacio público como materia arquitectónica. Mejor aún, los componentes que demandan los diferentes sistemas de espacios libres -que en clave de planificación territorial- se cuelan actualmente con trazos desdibujados entre el campo, la periferia y los centros de mayor densidad.

Recordando la elogiosa reseña que nos hacía Luis Fernández-Galeano ${ }^{9}$ definiendo al país como un oxímoron geográfico entre los valores paradójicos de lo local y lo global, viene a cuenta un cambio de giro, una revisión tan lúcida como reaccionaria en estos tiempos de inmejorable oportunidad de cambio. Quizás lo que señalaba a su vez Aravena Mori en su ponencia en Barcelona el año $2002^{10}$, el de tender a hojas cero, $a$ grado cero, sería la punta de lanza sensible e icónica del nuevo sustrato espacial ya no en la distracción que sugiere el proyecto disperso en el paisaje chileno con valor per se, sino en la creación de medios y artificios urbanos profundamente arraigados y presentes en nuestra forma de ser."

9 FERNÁNDEZ-GALEANO, Luis, en la introducción de la revista ARQUITECTURA VIVA N85, titulada "Último Chile", Madris, 2002.

10 PÉREZ, Fabián Gabriel, "Hacia la materia elemental", en: suplemento "Chile Arquitectura contemporánea", de la revista VISION 2, Josep María Montaner, Director, Barcelona, Escuela Técnica Superior de Barcelona, diciembre de 2003.

Revista de Urbanismo $N^{\circ} 11$ - Diciembre de 2004 